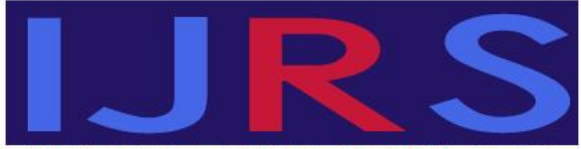

- INTERNATIONAL JOURNAL OF ROMA STUDIES .
Hipatia Press

www.hipatiapress.com

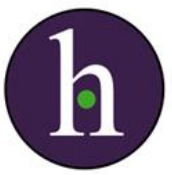

Instructions for authors, subscriptions and further details:

http://ijrs.hipatiapress.com

\title{
Vulnerable Populations' Access to Health Care: a Study of the Nomadic ‘Gypsy’ Narikuravars in Tamil Nadu, India
}

Cristina loana Dragomir ${ }^{1}$ and Mara Zafiu ${ }^{2}$

1) Institute for the Study of Human Rights, Columbia University. United States

2) University of Pennsylvania. United States

Date of publication: March $15^{\text {th }}, 2019$

Edition period: March 2019 - September 2019

To cite this article: Dragomir, C. \& Zafiu, M. (2019). Vulnerable populations' access to health care: a study of the nomadic 'Gypsy' Narikuravars in Tamil Nadu, India. International Journal of Roma Studies, 1(1), 58-83. doi: 10.17583/ijrs.2019.3034

To link this article: http://dx.doi.org/10.17583/ijrs.2019.3034

\section{PLEASE SCROLL DOWN FOR ARTICLE}

The terms and conditions of use are related to the Open Journal System and to Creative Commons Attribution License (CCAL). 


\section{Vulnerable Populations' Access to Health Care: a Study of the Nomadic 'Gypsy' Narikuravars in Tamil Nadu, India.}

Cristina Dragomir

Columbia University
Mara Zafiu

University of Pennsylvania

\section{Abstract}

This article explores how the nomadic Narikuravar from Tamil Nadu India, also known as the "Gypsy", access health care. The analysis is based on fifty-one openended, qualitative interviews conducted in early 2017 with Narikuravar women. This study differs from previous studies that explore how the poor, marginalized, and most vulnerable access health insurance in India by adding a new dimension: nomadism. Other work conducted with Romani (Gypsy) and nomadic communities concluded that these communities are reluctant to use state and private health care services. Our study concludes something very different. Not only did the Narikuravar women in our study actively seek health care access, they were eager to use government provided health insurance schemes. However, due to their limited education, poverty and mobile life style, they received health care only in emergency situations, and often needed to pay for those services from their small earnings, which increased their financial burden. We recommend further detailed research with the Narikuravar community, so that we can understand which health challenges they face. Development of policies to enhance women's education and employment is also a must. Such policies will translate into better access to health care as a basic human right.

Keywords: “Gypsy,” nomad, women, healthcare, India, Narikuravar 


\title{
El Acceso de las Poblaciones
}

\section{Vulnerables a la Atención Médica: un}

\section{Estudio de los Nómadas "gitanos"}

Narikuravars en Tamil Nadu, India

\author{
Cristina Dragomir \\ Columbia University
}

\author{
Mara Zafiu \\ University of Pennsylvania
}

\section{Resumen}

Este artículo explora cómo la comunidad indígena nómada Narikuravar, también conocidos como los "gitanos" de la zona de Tamil Nadu India, acceden a la atención médica. El análisis se basa en cincuenta y una entrevistas cualitativas, realizadas a principios de 2017 con mujeres Narikuravar. Nuestro estudio difiere de estudios previos centrados en estudiar el acceso de las poblaciones más pobres, marginadas y vulnerables al seguro médico en la India, ya que agrega una nueva dimensión: el nomadismo. Un trabajo previo realizado con comunidades Roma (gitanas) y nómadas concluyó que estas comunidades son reacias a utilizar los servicios estatales y privados de atención médica. No obstante, nuestra investigación concluye algo muy diferente, ya que observamos que las mujeres Narikuravar buscan activamente acceder a la atención médica, y poder disfrutar de los servicios de atención médica ofrecida por el gobierno. Debido a los bajos niveles de educación, la situación de pobreza en que se encuentran y el estilo de vida nómada, estas mujeres reciben atención médica solo en situaciones de emergencia, y con frecuencia deben pagar por estos servicios con sus escasos recursos, aumentando así su carga financiera. Recomendamos realizar una investigación más detallada con la comunidad Narikuravar, para poder entender a qué retos en el ámbito de salud se enfrentan. Es necesario también desarrollar políticas para mejorar la educación y el empleo de las mujeres Narikuravar, lo que se traducirá en un mejor acceso a la atención médica como un derecho humano básico.

Palabras clave: “Gitano”, nómada, mujeres, salud, India, Narikuravar 


\section{Dragomir \& Zafiu-Access to Health Care: 'Gypsy' India}

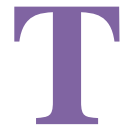

he United Nations Sustainable Development Goals state that all Member States should strive towards Universal Health Coverage (UHC) by 2030: "UHC means that all individuals and communities receive the health services they need without suffering financial hardship. It includes the full spectrum of essential, quality health services, from health promotion to prevention, treatment, rehabilitation, and palliative care." (UN World Health Organization, 2016). Moreover, the Universal Declaration of Human Rights of 1948 defined access to health care as a human right (Art. 25, UDHR, 1948). Marginalized and poor communities oftentimes do not have access to health care services, or, if they do, are at risk of being driven into poverty by catastrophic health care costs. In an attempt to help alleviate the circumstances these distressed communities encounter, governments across the globe have taken different initiatives. Some implemented free and subsidized health insurance schemes. Others increased their focus on prevention through public health initiatives like free vaccinations, and initiated training programs for medical staff that could reach out to remote areas.

Despite government attempts across the world to mitigate the financial burden and increase access to health, Universal Health Coverage in the most vulnerable parts of the world has not yet been accomplished, due largely to challenges such as financing, policy creation and implementation. Governments are also confronted with the formidable task of reaching people on a broad geographical spectrum, and educating them on the need for health care services and insurance. They are paying particular attention to traditionally marginalized groups, such as women and the poor. This attention is welcome and necessary, as it addresses the fact that how class hierarchies and intragroup gender dynamics could lead to creating obstacles in achieving access to health care. However, it starts from the premise that everyone is bound to one territory and can access health care through institutions that are responsible over that land. While not many in number, there are communities of people who cross borders, who move from place to place. As they do not have a large numerical presence, people on the move are often omitted from research and policy making. The following article addresses this gap and asks the following question: how does mobility influence women's access to health care? To answer this question, 
we conducted qualitative fieldwork in Tamil Nadu, India with women from a traditionally nomadic tribe: the Narikuravar, also called as "the Gypsy."

\section{Who are the Narikuravars?}

India has a long and entwined relationship with its mobile communities. These communities are still considerably influenced by the colonial categorization that officialized the term "criminals by birth" when referring to nomads. According to the Government of India (2016) list of "Denotified Tribes, Nomadic and Semi-Nomadic Tribes of India," the Narikuravars are a denotified nomadic community in the state of Tamil Nadu. The community's nomadism is a space of political and cultural contestation. The Narikuravars proudly declare themselves nomadic, but this self-identity comes at odds with the state's constant efforts to sedentarize them. Over past decades, the Tamil government has provided land and some form of housing to curtail the community's mobility. The Narikuravars accepted the government's programs, and obtained addresses that enabled them to acquire identification cards, like the 'Aadhar' card, which gives them access to welfare benefits. ${ }^{1}$ Nevertheless, they also engaged in a continuous negotiation of their nomadism, declaring that their settlements are instrumental, even if they do not live in them. While their lifestyle does not fit into the narrow definition of nomadism, as they are expected to be perpetually on the move, their lifestyle does not adhere to sedentarism either. If a label were to be imposed on them, it would probably be "semi-nomadic," but this would be a failure to acknowledge the community's self-identification, and will result in the misidentification of the issues confronted by the community as a result of their mobility (Dragomir, 2017).

Another label that is over imposed on the Narikuravars is "Gypsy." The Narikuravar community is referred to as "Gypsies," both formally (by researchers, activists and government representatives) and informally (by other Indian communities). ${ }^{2}$ The Indian usage of the term has deep historical roots in British Colonialism. It is a political category that has been used both in India and Europe to create and maintain a political, economic and social hierarchy that marginalized entire groups of people around the globe. Under the same label communities like the Romani, 


\section{Dragomir \& Zafiu-Access to Health Care: 'Gypsy' India}

Narikuravar or Banjaras were socially marginalized; they were excluded from political, economic and social participation, and they were refused equal human rights. Suffering from the consequences of this categorization brings the Narikuravars close to other Romani communities in other geographical areas. To date, there are no conclusive studies that can attest the genetic and cultural links between the Narikuravars and other Romani groups; however, the political consequences of being categorized as such, next to the economic and social similarities between the two, allows us to investigate access to social justice in general, and to health care in particular, that are connected to using the derogatory "Gypsy" terminology. Hence, in this context, the term "Gypsy" is understood as a political category that leads to the creation of discriminatory practices and policies. While many Narikuravars do not know the meaning of the term "Gypsy," they accept it as their identity, and appropriate it into their political and social activism aimed at achieving social justice and political participation, creating such organizations as the "Welfare Board of Gypsies".

The Narikuravar is a small community numbering 30,000 members across Tamil Nadu, and lacks electoral power in numbers. Similar to Romani groups around the world, the community is under-researched, and its health status is not well known. Narikuravars tell the story of their ancestors left the northern part of India and traveled south, where they still "roam around" today. Their traditional occupation was hunting jackals and other animals in the forest of the sub-Indian continent, but hunting was outlawed. Hence, they switched occupations to bead making and cleaning the streets (or sorting garbage). The Narikuravars are a regular presence near the Tamil temples, especially during holidays. They sell beads and other small, cheap, plastic products. Other times they are garbage scavengers, selecting and recycling garbage. As a result, they are the "invisible" city inhabitants, present in the center of the Indian metropolises, but utterly ignored. Most Narikuravars live in dire poverty, sleeping on the sides of roads, among piles of garbage, or, at times, in houses provided by the government, sheds or asbestos habitats far from any other communities. They often "go for business," which means leaving the settlement and spending days, at times months, on the road. Considering their specific 
lifestyle, the question arises: how do the nomadic Narikuravars, especially women, access health care services?

\section{Research design}

To answer the above question, we used as a springboard the previous scholarship of Oster (2009), Pandey and Ladusingh (2015), Raj (2011), Mathew (2012), Singh and Yadav (2000), Parashar (2005), Choudhury (2015), Kriti et al. (2012), and Devasenapathy (2016), which took into consideration gender and class as categories that might deter members of marginalized communities from accessing health care, and analyzed the intersection of these social factors with nomadism. In January 2017 we traveled to Chennai, Tamil Nadu and conducted field visits to places where Narikuravars typically engage in business. We also worked with Narikuravar community members to design the research questions, and trained local researchers to conduct interviews adhering to the Helsinki research accord.

Working together with the nomadic Narikuravar community is as exciting as it is daunting. The community's mobile character and internal orientation make research exceptionally difficult. Their settlements are not easy to locate geographically, and they are mostly uninhabited. Thus, the high unpredictability rate of their whereabouts lowers the chances of encounter and interview. Moreover, one's entry in the Narikuravar community is a long-enduring process. The community has strong internal ties, but is weary of strangers, keeping them at arm's length; hence gaining the Narikuravars trust takes time and consistent interest.

Interviews were conducted within Narikuravars' settlements, or in the public spaces where they manage their business. We conducted fifty-one open-ended interviews, which collected data about the Narikuravars' employment/labor practices and quantifiable wages, education and family life, as well as access to health care. We understand that fifty-one is a small number from which to generalize about a community, so we limit our analysis to the sample we studied, aiming to give a first insight into a severely under-studied and under-served community.

The Narikuravar women participating in this study were asked about their number of visits to hospitals or clinics. They were encouraged to 


\section{Dragomir \& Zafiu-Access to Health Care: 'Gypsy' India}

discuss at length their experiences with the medical system. The participants in this study were both in rural and urban environments, and were above eighteen years old. We paid particular attention to their level of education, and made efforts to include significant samples from each educational level within the community.

To encourage replies and blur the distinction between the insider and outsider researcher, we worked closely with representatives of the Narikuravar community. These representatives actively participated in the design of the questionnaire and conducted field interviews. This approach had the double advantage of having continuous input and reflection, as well as knowledge of the Narikuravar nomadic habits and destinations. The Narikuravar interviewers were also familiar with the community's language (i.e. Vagriboli), which enabled them to translate the questionnaire as needed. Moreover, they were able to foresee possible cultural differences that could translate into difficulties, such as women talking about prenatal health care in the presence of young men. However, their efforts were not without a backlash; being insiders also created obstacles in data collection. Some participants were reluctant to answer questions that were selfunderstood to interviewers from the same community. Moreover, simply being Narikuravar does not translate into total access to the community. The population is diverse; there is a clear class division, of which participants, mostly very poor,were much aware when faced with our interviewers, aspiring middle class. Other obstacles were various locations, long distances between the settlements, and transmitting the data back.

\section{Health Care in India for the Most Vulnerable}

Health care access for the most vulnerable of India's population, such as the marginalized, impoverished Narikuravar "Gypsy," has been a constant preoccupation for scholars, activists, international organizations and policy makers for more than a decade. Writing in 2001, Peters et al asserted that India's "health system is at a crossroad. (...) India is in the midst of a 'health transition', at varying rates depending on the state and population group" (Peters, 2010, p.1). Largely, women from poor communities of Scheduled Castes and Scheduled Tribes remain uniformed about much of the health 
subsystem. As a result, they are more likely to bore "the high burden of preventable diseases" (Ibid, p.3). Wondering "how can India meet the health needs of the most vulnerable segments of its population?", scholars created a report outlining the areas of need for accessing the health system, emphasizing the need for an effective, efficient and accountable health care system "to the Indian people and particularly to the poor" (Ibid, p. xvii-ix). There are large disparities between different classes' access to health care, with the poor, women, and Scheduled Tribes and Castes having the lowest access. For example, the poorest twenty percent of Indian population "have more than double the mortality rates, malnutrition, and fertility of the richest quintile" (Ibid p.1-2). According to Jayakhrishnan et al., in 2016 only ten percent of Indians had some form of health insurance. When hospitalized, they spend fifty percent of their annual expenditure on health care, and more than forty percent borrow money or sell their assets to cover hospitalization expenses. Moreover, the poor "are more likely to borrow money when they are hospitalized in the public sector than in the private sector," increasing their chances to slide into poverty as a result of high medical costs" (Dass, 2004, p. 11). Understanding these challenges, the government of Tamil Nadu established a vision for 2023, aiming "to become the number one State in India in terms of social indicators and also raise the standard of health delivery to international standards, ensuring universal access to health facilities" (Tamil Nadu Health Report).

To accommodate the health care needs of the poor and marginalized, the national Indian government developed a more efficient and equitable health financing system. This led to the creation of national, state and local health care schemes, with mandatory membership offering "socially acceptable and affordable package of benefits, pre-payment and risk pooling for people with different incomes and health status" (Peters et al . 2010). La Forgia and Nagpal (2012) analyzed these government health insurance schemes within the Indian context, exposing their benefits as well as their shortcomings. They argue that more needs to be done "to ensure more equal access to health care and suitable financial protection" (Goyal, 2012, p. 14). Aiming to promote a "system of health and medical services in India (...), which stresses the importance of preventive, promotive, public health and rehabilitation aspects of health care," the Tamil Nadu government created 


\section{Dragomir \& Zafiu-Access to Health Care: 'Gypsy' India}

the Chief Minister's Comprehensive Health Insurance Scheme in 2012 (Hiramani , 1997, p. 9). The government-sponsored scheme is available free of charge to families in Tamil Nadu with an annual income under Rs. 72,000 (approx. $\$ 1200$ per annum), and offers cashless hospitalization and procedures in private sector medical facilities (Tamil Nadu Government. Tamil Nadu Health Report). ${ }^{3}$

It is important to note that "gender inequality permeates family life in India," especially in terms of education and health (Ram, Strohschein \& Gaur, 2014). Females are at a "disadvantage in natality and education" and are "less likely to be literate, [or] continue in their education", which makes them among the most vulnerable in the society - particularly girls from indigenous groups (Echavarri \& Ezcurra, 2010). Even though Tamil Nadu has the second lowest index of gender inequality in the country, surpassed only by Kerala, women have a low labor participation rate, which negatively affects women's "access to health care" (Oster, 2008). Due to their economic dependency, women in poor and vulnerable communities are expected to have reduced access to health care services. Thus, this article focuses on women's access to health care services to reveal the challenges faced by nomadic women in India.

\section{Research Findings}

This study is double layered: it traces the community outlook and offers an understanding of the participants' access to health care. This approach is able to explain the need of the community in terms of accessing health care, while taking into consideration the general conditions of the community, which are vital, given the scarcity of research on the Narikuravars. While the two are interrelated in practice, we will analytically distinguish between these dimensions, and conclude by assessing the impact of community's characteristics on health access.

\section{The Narikuravar Population}

Many of the women interviewed were uncertain about their age or the age of their children. Because Narikuravars traditionally do not keep records of 
their births, even when they do give their age we cannot be certain it is accurate. A high degree of flexibility is needed in respect to age.

Education. Out of the women we interviewed, 15 did not go to school, one studied up to 12 standards (ISCED 3), one had a Bachelor's degree, and one had a Master's degree. The number of higher-educated women is significantly low in the community, as are women in the medical profession. However, education is not a factor of one's gender. In most cases, the participants' husbands or other male members of the family had similar education levels. Among our participants, we tracked a generational change. Elderly women were less educated, younger women attended school for a longer time, and children were more educated than their parents.

All interviewed Narikuravars were bilingual and spoke Tamil and Vagriboli. However, interviewers mentioned that their Tamil is colloquial, with little to no knowledge of formal or professional terms such as "insurance." Their limited education makes them rely on the spoken word, and media, such as radio and TV for obtaining information. Lack of education, high illiteracy, isolation from other communities, and limited communication skills in formal Tamil or English place the Narikuravar participants in a marginal position, with limited access to resources such as information about the health care system and health insurance.

Nomadism. All the Narikuravar women we interviewed told us where they lived, or their official address as per their identification cards used to access welfare services. However, they still consider themselves a nomadic community that "roams around." When we asked the Narikuravars how they explain their nomadism in the context of having a permanent address, they promptly replied that, while they use their address "to get the benefits" (i.e. access state assistance programs), they do not live at those locations. However, they admitted that at times they might use it as their base. This brings into view the contentious relationship between the communities in general and state policies aiming at sedentarizing them. In spite of undergoing changes over the past thirty years, including the Tamil government providing them with land, the Narikuravars still (proudly) view themselves as nomadic. This creates obstacles in accessing health care. As 


\section{Dragomir \& Zafiu-Access to Health Care: 'Gypsy' India}

they are rarely found at their address, the government employees in charge of health education and health care providers can't easily reach them. Among the Narikuravars we interviewed, mothers with young children were easier to reach, as they are more often present in one place than other Narikuravar women- i.e. margins of the road, or at their settlements. 35 out of the 51 women told us that government officials contacted them about immunization and crèche services for their children. However, when it came to insurance, their limited knowledge of its availability and utility proves that government messages hardly reach these women on the move. This creates a hierarchy where the less poor who live a less nomadic lifestyle have more access to information from government workers, while those who may not have formal settlements might be even more discriminated against, with less access to government programs.

The dire situation of the Narikuravar women who participated in our research in accessing health care is not unique. Sheikh and colleagues assert that, because they are not considered by policy-makers-who think the only way to access health care is to renounce their traditional nomadic lifestyle - nomads have worse health outcomes and indicators compared to other populations (Sheikh, Mahamoud and Househ, 2015). Omar further emphasizes that nomads "received little attention from the planners, economists, and government," and as a result they were left out of the "delivery of primary health care" (Omar, 1992). Similarly, Sachdev's study in Rajasthan argues that, in addition to "inaccessibility to health care, nomadic tribes are "reluctant to seek help for health issues" (Sachdev, 2012, p. 73). To address these issues, states responded with increased control over nomadic communities and a propensity towards sedentarization. However, as we can see in the case of the Narikuravars, while administrative settlements came into being, in practice their community is still highly mobile, and as a result, not able to access health care.

Class/ Poverty. In addition to their mobility, poverty is another striking characteristic of the community. Because the Narikuravars are understudied as a group, there is no clear data about the community's poverty level. The women we interviewed were not even certain about their income and 
outcome, making their economic situation unclear: "We do not earn or save for annual. We earn and spend daily. We earn around 100 to 200 IRS per day" (Pushpa, 22).

For self-employed members of the community engaged in commerce, it is difficult to accurately estimate their income, as they would need to deduct the costs of goods sold from their total earnings. Given their low education level and limited mathematical skills, we have found a lack of understanding of how to properly calculate their profit, and thus daily or monthly income.

Typically, the Narikuravars make less than 72,0000 IRS/ annum, which places the community below the poverty level accepted by both Tamil Nadu and India. However, because they are unaware of their income, they are unaware that they can access government-sponsored schemes, such as the Chief Minister's Comprehensive Health Insurance Scheme, which are designed to empower the poorest within the society. Their participation in the informal labor market through which they do not pay taxes raises yet another challenge to being classified in certain income groups and accessing free health insurance.

Women's poverty is further striking. The Narikuravar women in this study were both main caretakers of children and did not have access to any form of stable employment or wages. For example, Maarthal (28) lives in Kottur Maaligai, one of the settlements in Chennai where most people are garbage scavengers:

Due to recent delivery of my [recent] pregnancy, I could not able to take up a job anywhere ... But in case of self, I will do some small works that I may get from my neighbors and earn for my personal expense (Maarthal, 28).

Their poverty makes them highly dependent on government welfare programs, which do not always arrive on time:

Our house got destroyed during flood. No government helped us on these. They didn't even give compensation during rain and flood. We face hard by having children and surviving in this atmosphere. We do not have road, water facilities, we have to go to main road to fetch water. We do not have toilet facilities. Even if apply loan in 


\section{Dragomir \& Zafiu-Access to Health Care: 'Gypsy' India}

bank, however they asking more documents. A government official has not taken any initiatives. They only come here during election and ask for vote. We are suffering a lot without basic things like shelter, water, food (Nakma, 21).

Given that poverty drastically impacts access to health care, the Tamil government took action to ensure "health benefit maximization, priority for the worse off, financial risk protection and accountability" through The Chief Minister's Comprehensive Health Insurance Scheme. (Voorhoeve et al., 2014, p. 20) However, our study revealed that the scheme is still inaccessible to the Narikuravar women we collaborated with, as detailed in the following section.

\section{Health care and insurance.}

Using medical services. The community is renowned for its good knowledge of herbs and other natural medicine (Jackson, 1989). While the Narikuravars" "healing practices and epistemologies" are legendary, and the Narikuravars healers well known in Tamil Nadu, the women in our study, both in rural and urban areas, used and preferred allopathic doctors and medicine (Alex, 2009). Most women said they do not use natural medicine, but many said: "I don't use to follow our traditional practices. But I have heard people say it usually works" (Rekha, 29). Their preference allopathic medicine indicated their interest in obtaining health care.

The study revealed that many of our participants did not use formal medical services to address chronic and non-urgent aliments. Their most frequent use of allopathic treatment in clinics and hospitals occurred during pregnancy and birth: "During pregnancy delivery only. But even then, I didn't stay [in the hospital]" said Radhika Chandra (27). Her view was echoed by many women within the community, who often said, "I went to children hospital for my delivery" or for the children's vaccine. For their own health, Narikuravar women in this study seek medical attention in case of emergency: "last week went to hospital for high fever" (Pandiyammal, 28 ) or if they suffer from Malaria (Radha 25). In the instances when Narikuravar women like Radha and Pandiyammal needed medical treatment, they had to pay for their visit out of pocket because their 
expenses were not covered by insurance. Given thehigh costs (even a simple visit to the doctor costs $200 \mathrm{RS}$, approximately the equivalent of a day's earnings), the distance of medical facilities from their "settlements" or business places, as well as their inability to leave their children and out of fear of discrimination while receiving medical treatment, most of the Narikuravar women in our study did not have regular and preemptive access to health care.

A majority of the younger women we worked with, below thirty-five years of age, gave birth in hospitals and had follow ups with the medical staff. All interviewed Narikuravar women were informed about the necessary vaccines and decided to vaccinate their children. The vaccination experience was uneventful. The Narikuravar women in our group answered that they had no issues accessing vaccination, and reported no incidents. But they did report on one aspect: traveling to vaccination sites. While the women took the trip, they left behind their families, which might be difficult for mothers with multiple children and in charge of making beads or sorting garbage as a crucial part of their income.

Medical insurance and logistics. While most Narikuravar women participating in our research were familiar with the idea of having health insurance, interviewers had to explain the concept of "insurance" at length, finding different ways to phrase it. Nevertheless, out of 51 respondents, 35 women did not have health insurance, mainly because of a lack of education and limited information. The study also found that twenty-three of the women interviewed were not aware of, or did not know how to access the government-sponsored health insurance scheme, which they could receive free of cost. As Maarthal explained:

I don't know whom I need to contact. As we people are not much educated, we don't know about most of the schemes provided by government. So education stands here as our first priority in order to know the details of all other public things as well... Actually, I have seen about this in television, but I never had one (Maarthal, 28). 


\section{Dragomir \& Zafiu-Access to Health Care: 'Gypsy' India}

This highlights the importance of providing quality education to increase health awareness for a community whose women, on average, have not studied further than elementary school. Moreover, because of their relative isolation from other communities, and their lack of understanding of mainstream communication because of their low education level, the interviewed women get information about health insurance and the Chief Minister's Comprehensive Health Insurance Scheme mainly through local informal networks, or sometimes community leaders: I heard from people, I went and applied it but still didn't get the card, it's been eight months. (Bhavani, 27).

Additionally, many women reported at least an eight-months waiting time, pointing out other core challenges that restrict access, such as bureaucratic delay, and the lack of availability for reliable guidelines:

I got the insurance, but I was not able to use it in the government hospital because "they said that it will be valid in the central government hospitals in each district. So I didn't get any clear idea about the card and so I was not able to do this (Rajeswari, 37).

Even the small number of women in our sample who have health insurance were not able to use it, either because they lacked information or because the guidelines explaining how insurance can be utilized lacked clarity. This emphasizes that knowledge about health insurance, and specifically about the Chief Minister's Health Insurance Scheme, is poorly dispersed in the Narikuravar community. People are either unaware of the scheme's existence and their eligibility for coverage, or they do not understand the situations in which they can use it.

Payment. The Narikuravar women used both government and private hospitals, especially for child delivery. Out of the interviewed women, 23 reported that they used private hospital services for more serious medical conditions, while 19 chose public hospitals. However, the large out-ofpocket payments required deterred them from seeking continuous medical care. They opted for emergency care only: 
I was feeling very weak and anemic, I also lost weight and felt loss of appetite. I went to hospital and got medicine. They asked me to come for continues follow up but I didn't go due to economic condition. Because they charge 200 for fees and will write prescription for above 2000 IRS which is difficult for me to afford it. (...) 250 IRS and they gave medical prescription for 600 IRS. I paid it from my monthly salary. (Bhavani, 27)

Self-medication is also a common practice of the community, since it is the less costly option: "Sometimes due to financial crisis I do not go. I go to pharmacy and take tablets for fever and head ache". (Nakma, 21)

Previous studies show that the Narikuravar community also has genetically-transmitted health issues. For example, Dr. Sony's work with the community shows a high incidence of Alkaptonuria (also known as "black urine") among the Narikuravars from Tamil Nadu, establishing a founder effect and high degree of consanguinity (Sony, 2016) Given that the community only seeks medical care in extreme circumstances, many are not aware of this disease, which has an overall negative impact on the community's health, with many illnesses or diseases are left undiagnosed, and therefore untreated.

Discrimination and marginalization. The discrimination of the Narikuravars in Tamil Nadu is obvious, almost palpable. Like other communities categorized with the derogatory term "Gypsy," the Narikuravar community is often labeled as "dirty," "uncivilized," "uneducated," "rude," "aggressive" and "drunk." When seeing them, women hold their purses and children closer, and lock their pets inside their homes out of fear that the Narikuravars will steal and eat them. Narikuravar activists confirm that discrimination and marginalization are the most important obstacles in the development of the community.

Several women we interviewed voiced out the discriminatory practices they face: "Very bad response. Doctors treated us very badly. (...) They made us run here and there" (Jailalitha, 40); "First doctor didn't allow my husband for hospitalization just because we belong to this community" (Vashanti, 39). 


\section{Dragomir \& Zafiu-Access to Health Care: 'Gypsy' India}

Therefore, there is an additional layer of vulnerability that the community faces: besides not being able to access medical treatment because of the lack of education, lack of health insurance and the high outof-pocket cost, the community oftentimes receives a lower quality of care because of their cultural origin, through discrimination. Velakani explains the specific instances of stigma that the community faces when accessing care:

In hospitals, as soon as others see us they used to hold their nose as if we stink. They think we smell badly; we do not take bath like that. Even during work, people do not come nearby us. They stay away and buy things. They always humiliate us. Public used to threaten their children by saying they will hand over the children to us, as if we are dangerous or horrible people. Sometimes I shouted back at them and asked them to treat us as normal human being. (Velakani, 20)

Even if some Narikuravars had positive experiences accessing healthcare, the Narikuravar women we interviewed were aware of the typical reaction towards their community: "I was treated well even after knowing that we are Narikuravar community. Usually some doctors don't touch and see but here I got good experience" (Pushpa, 22).

The interviews suggest that facing discrimination is not an isolated event for the Narikuravar community, whether it is during education, work, or accessing health care. Acknowledging discrimination and its corrosive effects on the community is crucial for addressing the obstacles Narikuravar women in this study face in accessing health care, but it needs to be understood as a part of the process of self-determination of marginal communities, as a goal and not a given fact.

Gender Issues. Previous research (Dragomir forthcoming) shows that many Narikuravar women not only face discrimination from outsiders of their community, but they also occupy a marginal position. As our participants confessed, the Narikuravar community struggles with "child marriage": "Our community, we girls will get married at 15 or 16 years of 
age. Once we got married, we are into the hands of our husband" (Maarthal, $28)$;

I got married when I was an adolescent girl even when I didn't attain puberty. So I was not enough matured to understand society and myself at first. Even I didn't even know about my husband whether he was a gentleman or not. But later I came to know that he was a drunkard, so because of his habit our family is not able to earn a proper and stable income. And also as a contagion, our entire family has got affected from the habit including myself, my daughter and my daughter-in-law. (Rajeswari, 37)

Several participants strongly lamented early marriage and saw it as a part of their dire situation. They stated that marriage is highly regulated within the community, with women having little say in the decision-making process. All the women we interviewed were married. The community has very strict rules about one's life partner; members mostly marry within the community, with "outside marriage" leading to excommunication. This increased the participants' economic dependency on their community and on their husbands, and lowered their decision-making ability in accessing health care as needed.

Different from other Indian communities that exhibit a strong male child preference, the Narikuravar women we worked with did not manifest any gender preference and were happy to have "whatever God gives" (Rekha, 29). None of the women we interviewed went for child determination tests during their pregnancy and were content with the gender of the child. The Narikuravar women we interviewed had one or more children by the age of 25. ${ }^{3}$ Many women declared that not all pregnancies result in birth, with several of them having had abortions or lost the baby: "I was pregnant for three times. I was forced to abort twice the times by my husband and his family. (Maarthal, 28) ${ }^{4}$

The high incidence of abortion within the community emphasizes the need for sexual education and family planning, including practices of safe sex and distribution of contraceptives. Further studies and engagement with the community are needed, especially focused on developing a healthy family life. 


\section{Dragomir \& Zafiu-Access to Health Care: 'Gypsy' India}

\section{Conclusion: "Hailing the state"}

Typically, it is presumed that nomadic and "Gypsy" communities "are reluctant to seek help for health issues," which plays a significant role in their lack of access to health care. (Sachdev, 2012, p. 73) Moreover, the inadequate access is also assumed to be due to the lack of "trust between patient and care provider in the care-giving process" (Hanssens, 2016). It is further expected that: "When they seek medical care, Gypsies often come into conflict with medical personnel (...) Gypsies are often suspicious of non-Gypsy people and institutions, viewing them as a source of disease and uncleanliness" (Sutherland, 1992).

On the other hand, our study revealed that the "Gypsy" Narikuravar women we interviewed were willing to share their health issues, and hoped to engage outsiders of the community to receive help. However, they lack sufficient knowledge of the medical system, access to facilities and medical staff, and appropriate, usable health insurance that would alleviate the financial burden of their treatment. None of the Narikuravar women we interviewed manifested any reluctance towards medical facilities or staff, and all experienced and even preferred allopathic treatment when needed. They would like to go to hospitals, but they live far, and it is expensive; moreover, when they go they can be mistreated. Overall, the Narikuravar women participating in this research project did not refuse to seek medical care and positively engaged with the institutions of the state, like health care facilities and staff. They "hailed the state" (Mitchell, 2012), trying to move themselves into the radar of the state, while asking for equal access to human rights, such as health care.

\section{Recommendations}

The present work researched and reflected upon a small group of people, aiming to stir a conversation about how states ensure health care access for nomads in India. While the study refers to a particular Indian "Gypsy" community, it aims to offer data and participate in the lager decision on how other communities often referred to as "Gypsy" or "Romani," access social 
justice in general, and health care in particular. Upon finalizing this research, we have several recommendations.

First, there is an urgent need for consistent and constant attention to health issues for marginalized communities, which will inform policy makers, whom in turn need to make "culturally appropriate" programs that would impact the Narikuravars and other similar nomadic groups that are formally or informally categorized as "Gypsy" (Lee, 2011, p.166). Both qualitative and quantitative research with the community is needed in order to integrate and compare it with other similar communities and the population at large. Moreover, there is a need for further research on health habits and health culture within nomadic groups.

Second, to ensure that we address access to health care, attention needs to be paid on discrimination practices as well as on the denial of their marginalization. Qualitative, ethnographic work can reveal how Narikuravars are treated by other communities, and how Narikuravar women are treated within the community, especially when they interact with health care institutions.

Third, to further the Narikuravars' access to health care, we need to understand the difficulties encountered at the level of the healthcare system. Hence, healthcare providers also need to be interviewed, in order to provide a more thorough understanding of the health care system accessed by nomads.

Ultimately, it is important to create policies focusing on women who are nomads, like the Narikuravars, and with communities that have been placed in marginal position by being labeled as "Gypsy," providing them with the much-needed education and employment. As one of our participants put it, this would empower women to make health decisions within the community, and ultimately access health care, one of the basic human rights: "If we girls go to work, our community people don't respect us. Also, they do insult us with wrong talks or speeches. But in this generation, only if girls made themselves bold, they could survive as well" (Maarthaal, 28). 


\section{Dragomir \& Zafiu-Access to Health Care: 'Gypsy' India}

\section{Acknowledgment}

Special thanks to Sharan Chammu who coordinated the research team in Tamil Nadu. Without the assiduous efforts of the research coordinator this work would have not been possible.

This research was performed in accordance with the Declaration of Helsinki and has been approved by Institutional Review Board, SUNY Oswego (application \# 20150310db1).

\section{Notes}

1 To apply for the government-sponsored scheme, families need to go to health camps conducted by hospitals, where they need to present a ration card, an income certificate, a smart card for the scheme, obtained from the District Collectorate, and an Aadhar card, a biometric and demographic identification method.

${ }^{2}$ For example Krupa, an NGO in Tamil Nadu, conducted a study in 2016 aiming to improve the life of the Narikuravars in Tamil Nadu titled: "Education among the Gypsy Communities in and around Chennai, Kanchipuram, Tiruvellore Districts; Presentation to the State Planning Commission?" thus taking the "Gypsy" terminology as given.

${ }^{3}$ Except one who just got married.

4 This research did not focus on reproductive health of the Narikuravar women. However, during our fieldwork it became clear that further work needs to be undertaken to understand if and how Narikuravar women have access to pre- and postnatal care as well as to safe abortions. We acknowledge that in further research the following questions need to be addressed: What are the reasons for deciding in favor of abortion? Do primarily the women in the community take these decisions? Why would the family not want the children? How are the abortions done, in public or private health care, and if so who supports the costs?

\section{References}

Alex, G. (2009). Folk healing and the negotiation of shifting social identities in Tamil Nadu, India. MMG Working Paper, Munich, Germany: Max Planck Institute for the Study of Religious and Ethnic Diversity. Retrieved from http://www.mmg.mpg.de/fileadmin/user_upload/documents/wp/WP_ 09-05_Alex_Folk-healing.pdf

Choudhury, P. K. (2015). Explaining the Role of Parental Education in the Regional Variation in Infant Mortality in India. Asia \& the Pacific Asian Studies, 2(3), 544-572. doi: 10.1002/app5.97

Dass, S. K. 2004. Changing Trends in Health and Nutrition: Health and nutrition. India: Isha Books. 
Devasenapathy, N., Ghosh Jerath, S., Sharma, S., Allen, E., Zodpey, S. (2016). Determinants of Childhood Immunisation Coverage in Urban Poor Settlements of Delhi, India: a Cross-Sectional Study. BMJ Open, 6:e013015. doi: 10.1136/bmjopen-2016-013015 Dragomir, C. I. (2017). "STs, and the politics of exclusion," The Hindu.

Available at https://www.thehindubusinessline.com/opinion/sts-andthe-politics-of-exclusion/article9583825.ece

Echavarri R. A. and R. Ezcurra, (2010). Education and Gender Bias in the Sex Ratio at Birth: Evidence from India. Demography, 47(1), 449-

68. doi: 10.1353/dem.0.0089

Government of Tamil Nadu. Salient Features of the Scheme. Available at http://www.cmchistn.com/features.html

Govinfo. 2016. Chief Minister Comprehensive Health Insurance Scheme. Available at http://govinfo.me/chief-minister-comprehensive-healthinsurance-scheme/

Goyal, L. C. (2012). Introduction. In S. Nagpal and G. La Forgia (Eds.), Government-Sponsored Health Insurance in India. Washington DC: World Bank Publications.

Hanssens, L. G. M., I. Devisch, J. Lobbestael; Cottenie, B. \& Willems, S. (2016). Accessible Health Care for Roma: a Gypsy's Tale. A Qualitative In-Depth Study of Access to Health Care for Roma in Ghent. International Journal of Equity and Health, 15(38), 15-38. doi: 10.1186/s12939-016-0327-7

Hiramani, A. B. (1997). Cultural Correlates of Tribal Health, New Delhi, India: B.R. Publications

Jackson, W. (1989). Rituals of a 'Gypsy' Tribe: The Vagri or Narikuravar.

Presentation at Indianapolis Regional American Academy of Religion Conference, Bloomington, IN, April 8, 1989. Retrieved from

https://www.academia.edu/4413853/Rituals_of_a_Gypsy_Tribe_The _Vagri_or_Narikuravar

Jayakrishnan, T., Jeeja, M. C., Kuniyil, V. \& Paramasivam, S. (2016).

Increasing Out-Of-Pocket Health Care Expenditure in India-Due to

Supply or Demand? Pharmacoeconomics, 1(1), 105. doi:

10.4172/2472-1042.1000105 
81 Dragomir \& Zafiu-Access to Health Care: 'Gypsy' India

Joshi, K. M. (2010). Indigenous children of India: enrolment, gender parity and drop-out in school education. International Journal of Sociology and Social Policy, 30 (9/10), 545-558. doi:

10.1108/01443331011072299

Kriti, V., Vanneman, R., Desai, S. (2012). Linkages between Maternal Education and Childhood Immunization in India. Social Science \& Medicine, 75(2), 331-339. doi: 10.1016/j.socscimed.2012.02.043

Lee, K. W. (2011). A Comparison of the Health Status of European Roma and Australian Aborigines. Ethnicity and Inequality in Health and Social Care, 4(4), 166-185. doi: 10.1108/17570981111250831

Mathew, J. L. (2012) Inequity in Childhood Immunization in India: A Systematic Review. Indian Pediatrics, 49(3), 203-223. doi:

10.1007/s13312-012-0063-Z

Mitchell, L. (2012). Hailing the State: Political Arrival and Genealogies of Political Communication in Contemporary India. Presentation at the Panel "The Technologized Call: Subjects of Responsibility in MassMediated Religions and Cultures" AAA, San Francisco, CA, November 15, 2012.

Omar, M. A. (1992). Health Care for Nomads Too, Please. World Health Forum, 13(4), 307-310.

Oster, E. (2009). Does increased access increase equality? Gender and child health investments in India. Journal of Development Economics, 89(1), 62-76.

Pandey, A. \& Ladusingh, L. (2015) Socioeconomic Correlates of Gender Differentials in Poor Health Status among Older Adults in India. Journal of Applied Gerontology, 34(7), 879-905. doi:

10.1177/0733464813481850

Parashar, S. (2005). Moving beyond the Mother-Child Dyad: Women's Education, Child Immunization, and the Importance of Context in Rural India. Social Science \& Medicine, 61(5), 989-1000. doi: 10.1016/j.socscimed.2004.12.023

Peters, D. H., Yazbeck, A. S., Sharma, R. R., Ramana, G. N., Pritchett, L. H., \& Wagstaff, A. (2001). Better Health Systems for India's Poor. Washington DC: World Bank Publications, Denotified Tribes, Nomadic and Semi-Nomadic Tribes of India. Retrieved from 
http://socialjustice.nic.in/writereaddata/UploadFile/Draft\%20List\%2 0of\%20Denotified\%20Tribes\%20for\%20Mail.pdf

Raj, A. (2011). Gender Equality and Universal Health Coverage in India.

The Lancet, 377(9766), 618-619. doi: 10.1016/S0140-

6736(10)62112-5

Ram, U., Strohschein, L., \& Gaur, K. (2014). Gender Socialization:

Differences between Male and Female Youth in India and

Associations with Mental Health. International Journal of

Population Research, 357145, 1-13. doi: 10.1155/2014/357145

Sachdev, B. (2012). Perspective on Health, Health Needs and Health Care

Services among Select Nomad Tribal Populations of Rajasthan,

India. Antrocom Online Journal of Anthropology, 8(1), 73-81.

Sheikh, M., Mahamoud, A. \& Househ, M. (2015). Transforming Public

Health in Developing Nations. Hershey, PA.

Singh, P., \& Yadav, R. J. (2000). Immunization Status of Children in India. Indian Pediatrics, 37(11), 1194-1199.

Sony, (2016). Alkaptonuria - an Overview of ICMR Funded Project.

Presentation at the Department of Clinical Genetics Christian

Medical College and Hospital, Vellore, Tamil Nadu, June 29, 2016.

Sutherland, A. (1992). Gypsies and Health Care. West Journal of Medicine, 157(3), 276-280.

Tamil Nadu Government. Tamil Nadu Health Report, p. 193. Available at http://www.tn.gov.in/dear/Health.pdf

UN World Health Organization. Universal Health Coverage. Last modified December 2016.

http://www.who.int/mediacentre/factsheets/fs395/en/

Universal Declaration of Human Rights (UDHR), G.A. Res. 217A (III)

(1948), Art. xx. Available at http://www.un.org/Overview/rights.html

Voorhoeve, A., Edejer, T., Kapiriri, L., Norheim, O. F., Snowden, J.,

Basenya, O., Bayarsaikhan, D., Chentaf, I., Eyal, N., Folsom, A., Tun Hussein, R. H., Morales, C., Ostmann, F., Ottersen, T., Prakongsai, P., Saenz, C., Saleh, K., Sommanustweechai, A., Wikler, D., ... Zakariah, A. (2016). Three Case Studies in Making Fair Choices on the Path to Universal Health Coverage. Health and human rights, 18(2), 11-22. 
83 Dragomir \& Zafiu-Access to Health Care: 'Gypsy' India

Cristina-Ioana Dragomir is Adjunt Assistant Professor at Columbia University, Institute for Study of Human Rights, United States

Mara Zafiu is researcher at the University of Pennsylvania, United States

Contact address: dragc200@newschool.edu 